\title{
Discussion on the Competition Pattern of Chinese Wealth Management Market
}

\author{
Xiaoming Qiao ${ }^{1, \text { a }}$ \\ ${ }^{1}$ Journal Editorial Department, Yunnan Normal University, Kunming, Yunnan, China, 650092 \\ ${ }^{\mathrm{a} e m a i l,}$
}

Keywords: China, Wealth Management, Competition

\begin{abstract}
In 2013, the number of the affluent China reached 11970000 and the wealth gradually concentrated to the affluent. Commercial banks, trust companies, securities companies, insurance companies and third party financial institutions wealth management institutions have entered the wealth management market, formed the current wealth management market competition pattern. The financial industry of our country is still running separate operation, and the cooperation space between the future wealth management agencies is vast. In the background of the increasingly fierce competition in the market of wealth management, all wealth management organizations must segment the wealth management market and select the target wealth customer base to meet their wealth management needs.
\end{abstract}

\section{Wealth Management, Asset Management and Private Banks}

In the study of issues related to wealth management, often confused with wealth management, asset management and private banking concept among the three. Before examining the wealth management market competition, there is need to sort out the relationship between the three.

Wealth Management Wealth means the wealth management needs of the population, to provide comprehensive products and services, including financial planning, children's education, health care, investment and tax advice, retirement planning and estate arrangements. Wealth management emphasizes customer focus, focus on asset management and investment, is part of wealth management. Wealth management is currently more limited asset management or investment management, wealth management ca not really meet the target customers. When the main body of wealth management is bank, the range of wealth management is wider than the private bank: wealth management is for the general population, while private banks for high net worth (High Net Weight) customer base.

\section{Development Status of Chinese Wealth Management Market}

With the social and economic development, growth of personal property and improve financial supervision, expanding the potential demand for wealth management, wealth management services but between supply and demand is still some gaps.

The Needs of Wealth Management. China's number of millionaire households has surpassed Japan in 2012 from 1.5 million in 2013 to \$ 240 million, showing a strong trend of wealth creation. At the end of 2013, the number of mass affluent China reached 1197 million investments in the mainland can HNWIs asset size of more than 10 million RMB to 84 million, corresponding to the scale of our wealth reached 27 trillion RMB. It is predicted that in 2020 the total amount of the wealth management market will reach 227 trillion RMB, of which the private wealth management market growth rate will reach 97 trillion RMB. Growing national wealth, wealth gradually affluent concentrated, affluent by its own wealth management gradually to entrust professional bodies of wealth management, wealth management needs of an increasingly strong.

And developed countries have inherited the family wealth for generations compared to our affluent still in the "wealth creation" or first generation heritage stage, the relative lack of awareness of wealth management, wealth management needs of the general portfolio management services, after fully aware of wealth management, demand will be further released to education, health care, 
financial planning, tax planning, estate planning, family wealth, inheritance and other higher level of service changes.

The Supply of Wealth Management. Because wealth management having possession funds, low risk and strong levels of profitability and other advantages, wealth management services supplied to the market is increasing, but there are still less than the following: (1) our wealth management products and services related to the homogenization of serious, simple structure and lack of innovation, which is one of the most important factors restricting the development of the wealth management market. (2) Wealth management requires customer-centric, to meet their financial management needs as the goal, objective and fair stance, in order to avoid product-oriented marketing. But our wealth management market is still a product or sales-oriented, not yet formed a "customer-oriented" or "service-oriented" concept of wealth management, which cannot effectively meet the population's wealth personalized service requirements. (3) Wealth management requires employees to acquire knowledge of social, economic, legal and financial aspects, with a wealth of experience and good communication and interpersonal skills, but most of our wealth management employees from the original client manager and change from a financial planner, the lack of industry professional talents. [3]

The Competition Pattern of Wealth Management Market. Our wealth management market has formed commercial banks, securities companies, insurance companies, trust companies and third-party financial institutions, cross-business, the pattern of competition and cooperation. According to People's Bank of China statistics, by the end of 2013, trusts, bank financing, funds, securities firms and insurance asset management scale reached 10.9 trillion, 9.5 trillion, 6.22 trillion, 5.2 trillion and 0.68 trillion RMB. Short term, commercial banks, securities companies, insurance companies, trust companies will continue to be the wealth management marketplace, but the development of third-party financial institutions cannot be ignored, it would mean that the real growth of our wealth management market matures.

Commercial Banks. Internal and external factors the interest rate market and forcing commercial banks to finance the Internet to change the existing business model and to seek transformation from the traditional credit business to the development of intermediary business, commercial banks have entered the wealth management market. China's commercial banks wealth management through a process of constant development: a gradual transition from the traditional retail banking services to financial services, and then by the financial wealth management business to change the general sense, produces its sub-categories - private banking. In 2007, Bank of China launched the private banking business, marking the formation of sub-level wealth management landscape. Our private banking in its infancy, by the end of 2013, the number of customer specific information 9 domestic private banking services was 21.6 million and assets under management of 3.13 trillion RMB. Product category system to financing, loans and bond type products, it is difficult to extend to equity products.

Commercial Bank has become the first choice of HNWIs within financial management, leadership position in the wealth management market. Compared with the other subjects on the wealth management market, commercial bank has the following advantages: (1) has a widespread service network, large customer base and a good social reputation. (2) information on aspects of the unique advantages. Commercial banks can be controlled by the customer's credit card details, the proportion of mortgage and other information, which can be more profound understanding of its spending habits, debt and so on. (3) platform integration advantages. In the current financial environment separate supervision of commercial banks in providing their own financial products at the same time, other agencies may consignment products, with the advantage of platform integration.

Commercial banks a competitive disadvantage with the following: (1) product homogeneity is more serious. Simple financial products structure of commercial banks, the scope was restricted to the money market, bond market and insufficient foreign exchange market and other hedging products, product development and design innovation. (2) lack of ability to control investment risk. Rely on the spread between deposit and lending traditional business risk is relatively small, capital 
markets, wealth management investments to be carried out is bound to increase risk, commercial banks must strengthen risk control ability. (3) lack of high-quality client manager. Account Manager faces stressful work, making it difficult to provide quality services.

Trust. Our trust industry in rapid development period, entrusted assets have been expanding, trust products continue to enrich, at the end of the third quarter of 2014, the scale of trust assets to the trust management industry 12.95 trillion RMB. Our long-term dependence Trust Bank consignment products and third-party financial institutions, products from sale capacity are weak. The rapid expansion of business scale and trust products issued high costs and other factors have contributed to a trust company to enter the field of wealth management, seek business development, marketing channels and establish an independent building from product development to product sales of the entire process.

Trust known as the "financial department store," said, is the only cross-currency, capital and industrial areas of the three financial institutions have systems, products and other advantages, position in the wealth management market is important. Product design flexibility, innovation and strong focus on high-end customers, after the completion of the direct channel, trust companies can make customer channels and product design in parallel, to build their core competitiveness. Ping An Trust, Shanghai Trust, CITIC Trust and other companies have launched a trust family wealth inheritance or trust products ready to enter the field of family trust, trust development in the field of family trusts, land transfer trusts, pension trusts and other consumer trust and broad space for the future.

Trust asset management is weak, and the customer resource bottlenecks exist extensively on trust wealth management business to certain constraints. Trust as an intermediary in the profit model relies heavily on sales commissions and it is hard to complete the product of wealth to those who sell the service's role changes.

Securities. The end of 2010, GF Securities to set up wealth management center, marking the securities company entered the wealth management market. After the securities companies have also set up a wealth management center, and gradually expand the scale of asset management. By the end of 2013, the national securities companies entrusted with the management of the total capital of 5.2 trillion RMB, up sharply increased 175.13 percent.

In the investment and market familiarity, the securities company has a natural advantage, its range of investment flexibility, product variety, strong asset management capabilities, and with companies and business managers closely with a large number of high-end customers with a certain risk tolerance and therefore most likely to form a diversified integration brokers, investment banks, futures, direct investment and other business.

Securities wealth management business is still in its infancy in terms of wealth management business development at a competitive disadvantage relative to: (1) fewer channels. According to statistics, the assets under management of securities companies only $2 \%$ of bank, insurance $26 \%$, $33 \%$ trust, service outlets only $2.5 \%$ of the bank's stock of wealth of customers accounted for only 29\%. (2) the product structure is simple, most of the high investment in high-risk high-yield type. In contrast, the invest field of financial products commercial banks and trust companies to broader, product risks obvious layering. (3) facing more stringent regulation. Thanks to the competitive advantage of relatively loose supervision, banking, insurance, trust industry will gradually highlight, while securities firms are facing investment products, sales and other qualifications of strict supervision, which makes the risk of being marginalized, limit asset management scale and not conducive to a rich variety of asset management products.

Insurance Companies. With the advent of "big information management" era, the insurance company is facing important opportunities for development, entrusted with the future funding sources will be more extensive and with a variety of investment tools will be more complete. At the same time, insurance companies will also face a new challenge: to be market-oriented promotion, investment management and risk control capacity should be improved, and retain talent attraction needs to be improved.

The insurance company has unique advantages in wealth management services: (1) support 
functions. Insurance plays a central role in promoting the financial system and improve the social security system, focusing on insurance products for individuals and families "sickness and death," the rational planning and insurance protection, insurance protection fund functions in protecting the interests of investors is equivalent to commercial banks the deposit insurance system. (2) Mixed ability and improve services. The insurance company has basically realized securities investment fund business is fully licensed, offers a variety of wealth management focus from security planning, retirement, children's education and inheritance and so on. (3) contractual and long term. Short Term Insurance funding is for three years, or as long as a decade or two decades, on the one hand fit to perform advanced foreign "discretionary" asset allocation philosophy, some insurance asset management entrusted to other agencies to do the asset management when this has been done the attempt. On the other hand it can avoid the shadow banking credit conversion risk and maturity mismatch, etc., which is currently one of the main criticism of the wealth management market suffered. (4) insurance company in terms of wealth inheritance, with altruism, avoid debt and tax and other advantages.

The Third-Party Financial Institutions. For a long time commercial banks, insurance companies, securities and fund companies and other traditional financial institutions have been in a monopoly position, third-party financial institutions relatively slow development until around 2007 before rapidly emerging. British third-party organization to master wealth assets accounted for $80 \%$, nearly $60 \%$ of US financial products are sold by third-party financial institution. According to statistics, the number of third-party financial institutions around 2000, master of assets is roughly $6 \%-8 \%$ in the wealth management market share of only $5 \%$, a huge market potential third-party asset management.

Third-party financial institution independent of the banking, insurance, securities and other financial institutions, on behalf of the interests of customers, according to customer demand, relatively independent, objective and impartial manner for the customers of financial asset allocation and financial products screened.

Third-party financial institutions are still in their infancy, the industry threshold is low, uneven development, constantly exposed to many risks: (1) is still difficult to change the sales commission based development model. Third-party financial institutions consignment agencies products as the main business, sales commission are important source of profit. Currently configured as the client's product, the higher the risk, but you can get higher returns, subject to operational and performance pressure, third-party financial institutions have to focus on short-term gains and development. (2) the financial adviser uneven level. Easy to sell high commission but also higher risk products, the formation of misleading sales, enabling customers to invest into the trap of high risk. (3) the uncertainty over policy. Products under different regulatory systems, is dispersed in the regulatory state. Uncertain future policy is increasing its operational risks.

\section{Recommendations for Chinese Wealth Management Market Development}

To promote rapid and healthy development of the wealth management market, wealth management services should be increased to finance an important part of the overall development strategy. Each institution shall Wealth Management segment wealth management market, the development of competitive differentiation strategies, accurately grasp the customer's wealth management needs and provide wealth management services based on customer attributes, to maximize customer demand for wealth preservation and appreciation.

Based on Market Segmentation and Create Own Wealth Management Features. Wealth management market increasingly competitive, various wealth management institution shall use their own advantages to build business development characteristics, according to the scale of our wealth, risk tolerance, transaction characteristics and special preferences for the subdivision standard wealth management division of the target customer base, selective development and design-related products and services, in order to accurately grasp the needs of its wealth management and wealth management planning to form a unique competitive advantage.

Being Customer-Focus and Enrich the Existing Product Line. Under the premise of effective 
risk control, vigorously carry out innovative wealth management products to enrich the existing product line and investment choices is an important choice of wealth management to achieve a breakthrough. On the basis of innovative wealth management products, the agencies should strive to customer-centric. Only crossed in the early stages of product-centric, establish a customer-focused service concept and the formation of the corresponding service capabilities, wealth management services considered the true sense.

Accelerate the Training of Wealth Management Personnel. It should be through a variety of channels to speed up the training proficient in investment, financial, legal, tax planning and other expertise in wealth management personnel. On the one hand we can learn from foreign experience, establish and promote the wealth management professional teaching and research links and establish an independent Wealth Management Institute, conduct research, promote wealth management specialization and professionalism. On the other hand, we can improve the overall level of industry practitioners through the establishment of sound education and training system.

Deepen Cooperation among Wealth Managers. China's financial industry is still in place separate operation, various wealth managers in the conduct of the wealth management business have their own advantages and disadvantages, future cooperation in space between the agencies broad. Construction should be pluralistic and open architecture wealth management services in the fields of product, platform, information and human resources to carry out extensive cooperation to accelerate the overall development of the wealth management market in the short term.

Establish and Improve the Unified Regulatory Standards. With the growing size of wealth management, the need to establish the unified regulatory standards from the top-level design and improve the level of unified wealth management industry related laws and regulations, and market access for wealth managers, product distribution and risk control.

\section{References}

[1] Gu Sheng. The strategic thinking on health care development under the new situation wealth management business [J] Wealth Management, 2008, (11): 46-49

[2] Li Liuyu, Liu Mingkang. The gaps and challenges China wealth management industry [J] International Financing, 2014, (3): 44-45

[3] Hu Wentaoao. Develop new wealth management business [J] new financial, 2006, (5): 39-41.

[4] Zhao Ye. The wealth management development prospects and market strategy analysis [J] Northern economy, 2010, (12): 54-56.

[5] $\mathrm{Hu}$ Jiang. Financial asset management company wealth management business[J] China Finance, 2013, (9): 86-87

[6] Wang Sheng, Hu Lingyan. Wealth Management: Global Trends, Prospects and Chinese commercial banks Countermeasures [J] South China Finance, 2013, (3): 83-87.

[7] Pan Xinmin. Urgency to Reject the Chinese wealth management trends and countermeasures [J] Financial Times, 2012, (8): 103-105 